\title{
Somewhere between no-blame culture and treating medical errors as crimes
}

\author{
Derrick KS Au *, LMCHK, FHKAM (Medicine) \\ Director, Centre for Bioethics, Faculty of Medicine, The Chinese University of Hong Kong, Shatin, Hong Kong \\ Chairman, Hospital Authority Clinical Ethics Committee, Hong Kong \\ * Corresponding author: ksau@cuhk.edu.hk
}

Hong Kong Med J 2018;24:330-2

DOI: $10.12809 / \mathrm{hkmj} 185080$

In an extensively referenced and incisive article, Prof Gilberto Leung lays out the controversial issue of medical manslaughter. ${ }^{1}$ In English law, the associated legal offence is termed gross negligence manslaughter (GNM). Doctors can be charged and convicted of this offence when a duty of care is breached, with grossly negligent acts or omissions causing patient death. Prosecution of doctors for GNM is rare but on the rise in the UK, and doctors have expressed concerns about the impact such investigations and prosecutions have on staff morale and health services. ${ }^{2}$

The law with respect to GNM was clarified in the 1994 Adomako case ${ }^{3}$ in which the anaesthetist in charge of a patient during an eye operation failed to notice the disconnection of an oxygen pipe for 6 minutes, and the patient died as a result. The jury in this case was directed to "to consider whether that breach of duty should be characterised as gross negligence and therefore as a crime". What then constitutes 'gross' negligence? The guidance provided by Lord Mackay was that the jury should judge how far the defendant's conduct departed from the standard of care, and the conduct should be 'so bad' as to amount to a criminal act. In her award-winning law reform essay, Katherine Wright ${ }^{4}$ considered the problem of uncertainty regarding the legal test for gross negligence in some detail. She noted that even prosecutors themselves had difficulty articulating their interpretation of gross negligence, and that a solid prosecution policy for this serious charge is lacking. The decision whether or not to prosecute may not be arbitrary but does seem particularly reliant on the prosecutor's own moral frame or even gut feelings. ${ }^{4}$

The field of GNM law appears to be oblivious to the field of patient safety improvement, where 'blame-free culture' is the paradigm. Jeremy Hunt, the UK Health Secretary, delivered a passion-filled speech titled "From a blame culture to a learning culture" in his address at the Global Safety Summit in March 2016. In the speech, he quoted a 1990 case of 'a bright 24-year-old medical school graduate' who started his first job in medicine as a pre-registration house officer, and in his first month of duty, he wrongly injected a highly toxic chemotherapy drug to a patient's spine. The 16-year-old patient died, and the medical house officer and another colleague were prosecuted for medical manslaughter and given suspended jail sentences. The conviction was eventually overturned by the Court of Appeal.

Hunt $^{4}$ regretted that "...the real crime was missed: as the legal process rumbled on, exactly the same error was made in another National Health Service (NHS) hospital and another patient died because our system was more interested in blaming than learning". He went on to say, "The blame culture doesn't just create fear [among] doctors. It causes heartbreak for patients and their families..." Blocked by fear of blame, defensive health care workers shut grieving families out when unexpected patient death occurs. ${ }^{5}$ Hunt insisted that a blame-free environment promotes learning and openness and that prosecuting such medical mistakes as criminal offences does not help. ${ }^{5}$

How do we reconcile the observation that, on the one hand, the UK Health Secretary made such a passionate plea for a non-punitive approach, and on the other hand, that investigations and prosecutions for GNM are on the rise? Is the UK of split mind?

Winding the clock back by two decades may help us see how the pendulum has been swinging between the blame-free paradigm and hard legal sanctions. The story might have begun in the US. In November 1999, the Institute of Medicine (now the US Academy of Medicine) issued a groundbreaking report To Err is Human: Building a Safer Health System. ${ }^{6}$ With this, the US and the rest of the world embarked on a decade-long pursuit of a patient safety agenda. No-blame or blame-free culture became buzzwords throughout the decade. ${ }^{7,8}$

The premises of this patient safety movement can be simply stated: first, medical errors are common and cause many patient injuries and even deaths; second, most medical errors are caused by underlying unsafe practices, work processes, and poor systems. This is not to say that human factors are not important, but the common notion of bad physicians being the root cause of bad care appeared unfounded in the vast majority of cases. To build safety systems in health care, it is essential to encourage openness in incident reporting and root 
cause analysis. Lessons will not be learned if the root causes cannot be discussed openly without fear of retribution.

Perhaps the pendulum swung again in 2010 with the NHS Mid Staffordshire Trust tragedy. 'Tragedy' is a euphemism for a fairly large scandal, which revealed hundreds of patients having died needlessly as the result of substandard care and staff failings at two hospitals in Mid Staffordshire between January 2005 and March 2009. A public inquiry led by Robert Francis QC produced the Francis Report, ${ }^{9}$ in which 290 recommendations for improvement were made.

The Francis report was not enough to weather the political storm. In 2013, the UK Prime Minister commissioned Professor Donald Berwick from the US to study Mid Staffordshire's various accounts and the recommendations of the Francis report to distil lessons to be learned by the UK Government. Berwick, the co-founder of the Institute of Healthcare Improvement and chair of the National Advisory Council of the Agency for Healthcare Research and Quality, is a fervent champion of health care quality and safety. The Berwick report released in October 2013 indicated a complete systems failure during the Mid Staffordshire Trust tragedy. ${ }^{10}$ It recommended a broad culture change in the NHS: "The way out is through learning, curiosity, commitment, and empathy rather than anger, fear and blame". ${ }^{10}$

Berwick's non-punitive and encouraging approach was hailed by some as having completely dismissed "the nonsense of criminal sanctions in healthcare".11 This overlooked the part of the report that called for effective regulations to be strong, focused, and detailed, as well as a recommendation "to build a hierarchy of regulatory responses, including making new criminal sanctions" (Recommendation 10, Section VIII). ${ }^{10}$ The argument was that existent criminal sanctions (including GNM) are not wide enough in scope, and therefore that the UK Government should introduce new sanctions "in cases where healthcare workers or organisations are unequivocally guilty of willful or reckless neglect or mistreatment of patients". The Berwick report drew on parallels with existing laws that protect mentally incapacitated and mentally ill people under institutional care.

Authors of the Berwick report were conscious of the apparent contradiction of this recommendation on new criminal sanctions with the celebrative 'blame free' learning culture advocated in the rest of the report. The report emphasised that supporting NHS staff and hospitals in learning from errors and holding them criminally accountable are not mutually exclusive approaches. This assertion that we can have the best of both worlds (being blamefree and imposing criminal sanctions as a deterrent at the same time) seems neither self-evident nor evidence-based.

Would criminalising health care professionals for wilful neglect improve patient safety? The UK Government has yet to make a decision on this particular recommendation in the Berwick report. The issue has been debated: one proponent has argued that criminal sanctions have worked in public health law. An example is the success of making seatbelt wearing legally compulsory, which has effectively saved many lives. ${ }^{12}$ However, the example of seatbelt wearing is a poor one: modern health care is extremely complex, and risk mitigation in medical practice is dissimilar from the single requirement of seatbelt buckling.

Medical manslaughter is a difficult subject, and we should be mindful that protection of doctors is not primarily at stake. Insisting on a totally blamefree culture may be idealistic and can be mistaken for not accepting responsibility when medical harm occurs. Even if we accept that medical errors, including fatal medical incidents, are often caused by a mix of systemic and human factors, doctors and management should be accountable for the parts for which they are responsible. Accordingly, accountability and 'just culture' have been proposed. ${ }^{13,14}$ Prosecution for medical manslaughter may be justified in extreme cases of recklessness and blatant violation of standards of care. The difficulty lies in drawing a line between simple negligence due to fleeting lapses of attention under overworked conditions and gross negligence that is truly reckless. As discussed by Leung, ${ }^{1}$ gross negligence is not a clearly defined legal concept. ${ }^{1}$ We need a sustainable health care system that cherishes positive efforts to learn and improve care and is just to the public and fair to professionals. Open discussion is the way forward.

\section{Declaration}

The author has disclosed no conflicts of interest. The author had full access to all data, contributed to the paper, approved the final version for publication, and takes responsibility for its accuracy and integrity.

\section{References}

1. Leung GK. Medical manslaughter in Hong Kong-how, why, and why not. Hong Kong Med J 2018;24:384-90.

2. Medico-Legal Committee. The British Medical Association. Medical and gross negligence manslaughter. Available from: https://www.bma.org.uk/collective-voice/committees/ medico-legal-committee/medical-manslaughter. Accessed 14 May 2018.

3. Rv Adomako [1995] 1 AC 171.

4. Wright $\mathrm{K}$. When clinical becomes criminal: reforming medical manslaughter. Law Reform Essay. Bar Council of UK. Available from: https://www.barcouncil.org.uk/ media/627460/_35_law_reform_essay.pdf. Accessed 18 May 2018.

5. Hunt J. From a blame culture to a learning culture. Mar 2016. Available from: https://www.gov.uk/government/ 
speeches/from-a-blame-culture-to-a-learning-culture. Accessed 18 May 2018.

6. US Institute of Medicine Committee on Quality of Health Care in America. In: Kohn LT, Corrigan JM, Donaldson MS, editors. To Err is Human: Building a Safer Health System. Washington, US: National Academies Press; 2000.

7. Lilleyman J. A blame-free culture in the NHS: quixotic notion or achievable ambition? Perfusion 2005;20:233.

8. Elmqvist KO, Rigaudy MT, Vink JP. Creating a no-blame culture through medical education: a UK perspective. J Multidiscip Healthc 2016;9:345-6.

9. UK Government. Report of the Mid Staffordshire NHS Foundation Trust public inquiry. Feb 2013. Available from: https://www.gov.uk/government/publications/reportof-the-mid-staffordshire-nhs-foundation-trust-publicinquiry. Accessed 13 Mar 2017.

10. Department of Health and Social Care, UK Government.
Berwick review into patient safety: recommendations to improve patient safety in the NHS in England. 6 Aug 2013. Available from: https://www.gov.uk/government/ publications/berwick-review-into-patient-safety. Accessed 18 May 2018.

11. Berwick report highlights nonsense of criminal sanctions in healthcare. Aug 2013. Available from: https://www. pharmaceutical-journal.com/news-and-analysis/berwickreport-highlights-nonsense-of-criminal-sanctions-inhealthcare/11124155.article. Accessed 21 May 2018.

12. Bibby J, Tomkins C. Would criminalising healthcare professionals for wilful neglect improve patient care? BMJ 2014;348:g133.

13. Walton M. Creating a "no blame" culture: have we got the balance right? BMJ 2004;13:163-4.

14. Wachter RM, Pronovost PJ. Balancing "no blame" with accountability in patient safety. N Engl J Med 2009;361:1401-6. 